\title{
CRITÉRIOS PARA IDENTIFICAÇÃO DE ÁREAS PARA IMPLANTAÇÃO DE ATERRO SANITÁRIO
}

\section{CRITERIA FOR IDENTIFICATION OF AREAS FOR THE IMPLEMENTATION OF SANITARY LAND}

\section{Mayara Maezano Faita Pinheiro ${ }^{1}$; Lucas Prado Osco ${ }^{2}$; Tatiana Sussel Gonçalves $^{3}$ Ana Paula Marques Ramos ${ }^{4}$}

\author{
${ }^{1}$ Universidade do Oeste Paulista - UNOESTE, Mestranda pelo Programa de Pós- \\ Graduação em Meio Ambiente e Desenvolvimento Regional \\ E-mail: mayarafaita@gmail.com \\ ${ }^{2}$ Universidade do Oeste Paulista - UNOESTE, Doutorando pelo Programa de Pós- \\ Graduação em Agronomia \\ E-mail:pradoosco@gmail.com \\ ${ }^{3}$ Universidade Estadual Paulista - UNESP, Instituto de Ciência e Tecnologia - Campus de \\ São José dos Campos - SP \\ E-mail: tatiana.mendes@unesp.br \\ ${ }^{4}$ Universidade do Oeste Paulista - UNOESTE, Pós-Graduação em Meio Ambiente e \\ Desenvolvimento Regional \\ E-mailanaramos@unoeste.br
}

RESUMO - O objetivo deste trabalho é levantar os critérios restritivos e ponderáveis para identificação de potenciais áreas para a implantação de aterro sanitário. 0 método foi dividido em: (1) consulta às leis, normas técnicas e resoluções; (2) consulta às recomendações relacionadas ao objeto de estudo (aterro sanitário); e (3) descrição dos critérios restritivos e ponderáveis. $O$ primeiro resultado foi um apanhado geral sobre as principais legislações, resoluções, normas e portarias relacionadas à implantação de um aterro sanitário. Como segundo resultado, obtivemos os critérios de ordem restritiva e ponderável. Existem diversos critérios ponderáveis, porém, devido à dificuldade de encontrar alguns dados e a generalidade de algumas informações, podese optar por considerar apenas os critérios ponderáveis pertinentes à área de estudo. Concluímos que este trabalho contribui para a facilidade de entendimento e acesso às leis, resoluções, normas e portarias vigentes, relacionadas a implantação de aterro sanitário. Porém, há a necessidade ainda de elaboração de licenças ambientais, conforme exigido pelo órgão ambiental, nos quais exigem estudos mais detalhados e análises específicas para, assim, definir a área para implantação de aterro sanitário.

Palavras-chave: Aterro Sanitário. Legislações Vigentes. Critérios restritivos e ponderáveis.

Recebido em: 27/08/2018

Aprovado em: 05/09/2018
ABSTRACT - This work aims to identify the restrictive and ponderable criteria for the identification of potential areas for implantation of a sanitary landfill. The method was divided into (1) consultation of laws, technical standards and resolutions; (2) consult the recommendations 
related to the object of study (landfill); and (3) description of restrictive and ponderable criteria. The first result was a general overview of the main laws, resolutions, norms and ordinances related to the implementation of a sanitary landfill. As a second result, we obtained the criteria of restrictive and ponderable order. There are several ponderable criteria, however, due to the difficulty of finding some data and the generality of some information, one can choose to consider only the ponderable criteria pertinent to the study area. We conclude that this work contributes to the ease of understanding and access to the laws, resolutions, norms and ordinances in force, related to the implantation of a sanitary landfill. However, there is still a need for the development of environmental permits, as required by the environmental agency, in which they require more detailed studies and specific analyzes to define the area for landfill.

Keywords: Landfill Sanitary. Current Legislation. Restrictive and ponderable criteria. 


\section{INTRODUÇÃO}

A lei 12.305 de 2 de agosto de 2010 institui a Política Nacional de Resíduos Sólidos no Brasil. Dentre as diretrizes apresentadas na lei, o inciso VIII do artigo $3^{\circ}$ define:

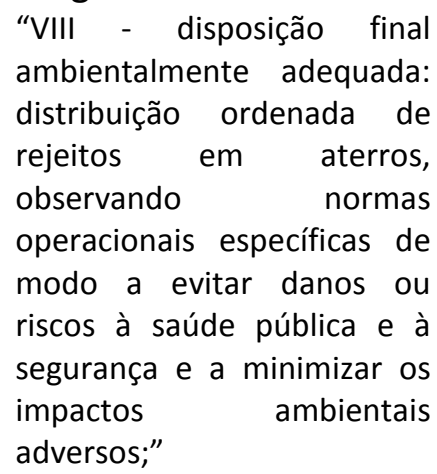

Mesmo com a instituição desta lei, o Brasil, ainda, enfrenta problemas de disposição final inadequada dos resíduos sólidos, como é o caso dos lixões. De acordo com a ABRELPE (2016), dos 91\% de resíduos sólidos coletados, $24,2 \%$ são dispostos em aterro controlado e $17,4 \%$ em lixões. Diante deste cenário, e considerando os agravos da disposição inadequada dos resíduos sólidos, como contaminação do solo, contaminação do lençol freático e contribuição para a proliferação de vetores e doenças, observa-se a necessidade de ampliar formas adequadas de disposição final de resíduos sólidos, como por exemplo, a implantação de aterros sanitários.

Para tanto, encontrar uma área adequada para implantação de aterro sanitário não é uma tarefa fácil, nem simples, pois envolve a consideração e a integração de uma série de critérios. Assim, é necessário conhecer e atender as leis, normas e recomendações existentes, isto tanto a nível federal, estadual quanto municipal. Os critérios definidos nessas diferentes instâncias abrangem as esferas de ordem ambiental e socioeconômica, e podem ser classificados em restritivos, quando obrigatórios, pois são embasados em leis, normas e resoluções; ou em critérios ponderáveis, quando não obrigatórios, porém são importantes para a definição de área para aterro sanitário e, por isso, são recomendados por estudos $\mathrm{e}$ normas.

Embora a temática de definição de área para aterro sanitário não seja algo recente na literatura, como mostra um levantamento feito por De Feo e De Gisi (2014), ainda, recentemente, é possível identificar trabalhos nesse contexto e que, muitas vezes, utilizam uma combinação distinta de critérios para essa tomada de decisão, como se constata, por exemplo, nos trabalhos de Carrilho et al. (2018), Spigolon et al. (2018), Colvero et al. (2018), Torabi-Kaveh et al. (2016), Rahmat et al. (2016), Motlagh e Sayadi (2015), Demesouka et al. (2014) e Nascimento e Silva (2014). Nesse sentido, o objetivo deste trabalho é levantar os critérios restritivos e ponderáveis para a identificação de potenciais áreas para a implantação de aterro sanitário.

\section{MÉTODO}

Três etapas compõe o método para a elaboração desse trabalho: (1) consulta às leis, normas técnicas e resoluções em nível federal; (2) consulta às recomendações relacionadas ao objeto de estudo (aterro sanitário); e (3) descrição dos critérios restritivos e ponderáveis. Para tanto, realizamos uma busca em base de dados disponíveis em websites oficiais, a qual permitiu levantar as legislações e normas vigentes, assim como, as recomendações disponíveis. Para facilitar a descrição dos critérios, classificamos em restritivos, ou seja, são pré-requisito para implantação de um aterro sanitário, e critérios ponderáveis.

\section{RESULTADOS E DISCUSSÕES}

Como primeiro resultado, obtivemos um apanhado geral sobre as principais legislações, resoluções, normas e portarias relacionadas à implantação de um empreendimento como aterro sanitário. Para facilitar a análise dos resultados, estas foram separadas por categorias como: Legislação (Tabela 1), Resolução do Conselho Nacional do Meio Ambiente (CONAMA) (Tabela 2), 
Normas ABNT NBR (Tabela 3) e Portaria (Tabela 4).

As leis, resoluções, normas e portaria, apresentadas nas Tabelas de 1 a 4, representam de forma abrangente as principais considerações sobre a implantação de empreendimentos como aterro sanitário, bem como as sanções penais e administrativas derivadas de condutas e atividades lesivas ao meio ambiente, conforme a Lei de Crimes Ambientais (Lei $\mathrm{n}^{\circ}$ 9.605/98).

Como um segundo resultado, obtivemos os critérios de ordem restritiva e ponderável. As Tabelas 5 e 6 apresentam, respectivamente, os principais critérios restritivos e ponderáveis que foram agrupados na esfera ambiental e socioeconômica. Essas tabelas estão organizadas da seguinte forma: Critério (nome do critério), Restrição/Recomendação (tipo de restrição ou recomendação definida), Tipo de Critério (restritivo ou ponderável), Fonte de informação (a fonte da restrição/recomendação), e Fonte de dados (as principais fontes de dados geográficos). Os Sistemas de Informação Geográfica (SIG) são ferramentas fundamentais em estudos de definição de área para aterro sanitário, pois otimizam as tarefas de armazenamento, processamento e visualização de dados geográficos.

Os critérios restritivos, ou seja, condicionantes para a definição de possíveis áreas para aterro sanitário, devem ser sempre atendidos. Dentre os critérios ponderáveis pode haver variações conforme a disponibilidade do dado, considerando que são recomendações, ou seja, caso possam ser atendidos, beneficiará as esferas ambiental e socioeconômica.

Tabela 1. Compilação das principais leis relacionadas à implantação de aterro sanitário.

\begin{tabular}{|c|c|}
\hline Legislação & Descrição \\
\hline $\begin{array}{l}\text { Lei } n^{\circ} \\
5.197 / 1967\end{array}$ & Dispõe sobre a proteção à fauna e dá outras providências. \\
\hline $\begin{array}{l}\text { Lei } n^{\circ} \\
6.938 / 1981 \\
\end{array}$ & $\begin{array}{l}\text { Dispõe sobre a Política Nacional do Meio Ambiente, seus fins e mecanismos de } \\
\text { formulação e aplicação, e dá outras providências. }\end{array}$ \\
\hline $\begin{array}{l}\text { Lei } n^{\circ} \\
7.653 / 1988\end{array}$ & $\begin{array}{l}\text { Altera a redação dos artigos 18, 27, } 33 \text { e } 34 \text { da Lei no 5.197, de } 3 \text { de janeiro de } \\
1967, \text { que dispõe sobre a proteção à fauna, e dá outras providências. }\end{array}$ \\
\hline $\begin{array}{l}\text { Lei } n^{\circ} \\
9.605 / 98\end{array}$ & $\begin{array}{l}\text { Dispõe sobre as sanções penais e administrativas derivadas de condutas e } \\
\text { atividades lesivas ao meio ambiente, e dá outras providências. }\end{array}$ \\
\hline $\begin{array}{l}\text { Lei } n^{\circ} \\
9.985 / 2000\end{array}$ & $\begin{array}{l}\text { Regulamenta o art. } 225, \S 10 \text {, incisos I, II, III e VII da Constituição Federal, institui } \\
\text { o Sistema Nacional de Unidades de Conservação da Natureza e dá outras } \\
\text { providências. }\end{array}$ \\
\hline $\begin{array}{l}\text { Lei } n^{\circ} \\
11.284 / 2006\end{array}$ & $\begin{array}{l}\text { Dispõe sobre a gestão de florestas públicas para a produção sustentável; institui, } \\
\text { na estrutura do Ministério do Meio Ambiente, o Serviço Florestal Brasileiro - SFB; } \\
\text { cria o Fundo Nacional de Desenvolvimento Florestal - FNDF; altera as Leis nos } \\
\text { 10.683, de } 28 \text { de maio de } 2003,5.868 \text {, de } 12 \text { de dezembro de } 1972,9.605 \text {, de } 12 \\
\text { de fevereiro de } 1998,4.771 \text {, de } 15 \text { de setembro de } 1965,6.938 \text {, de } 31 \text { de agosto } \\
\text { de } 1981 \text {, e } 6.015 \text {, de } 31 \text { de dezembro de } 1973 \text {; e dá outras providências. }\end{array}$ \\
\hline $\begin{array}{l}\text { Lei } n^{\circ} \\
12.305 / 2010\end{array}$ & $\begin{array}{l}\text { Institui a Política Nacional de Resíduos Sólidos; altera a Lei no 9.605, de } 12 \text { de } \\
\text { fevereiro de 1998; e dá outras providências. }\end{array}$ \\
\hline $\begin{array}{l}\text { Lei }^{\circ} \\
12.651 / 2012\end{array}$ & $\begin{array}{l}\text { Dispõe sobre a proteção da vegetação nativa; altera as Leis nos } 6.938 \text {, de } 31 \text { de } \\
\text { agosto de } 1981,9.393 \text {, de } 19 \text { de dezembro de } 1996 \text {, e } 11.428 \text {, de } 22 \text { de dezembro } \\
\text { de } 2006 \text {; revoga as Leis nos } 4.771 \text {, de } 15 \text { de setembro de } 1965 \text {, e } 7.754 \text {, de } 14 \text { de } \\
\text { abril de } 1989 \text {, e a Medida Provisória no } 2.166-67 \text {, de } 24 \text { de agosto de } 2001 \text {; e dá } \\
\text { outras providências. }\end{array}$ \\
\hline
\end{tabular}

Fonte: Elaborado pela autora (2018). 
Tabela 2. Compilação das principais resoluções CONAMA relacionadas à implantação de aterro.

\begin{tabular}{|c|c|}
\hline $\begin{array}{c}\text { Resolução } \\
\text { Conselho } \\
\text { Nacional de Meio } \\
\text { Ambiente } \\
\text { (CONAMA) }\end{array}$ & Descrição \\
\hline$N^{\circ} 237 / 1997$ & $\begin{array}{l}\text { Dispõe sobre a revisão e complementação dos procedimentos e critérios } \\
\text { utilizados para o licenciamento ambiental. }\end{array}$ \\
\hline$N^{\circ} 305 / 2002$ & $\begin{array}{l}\text { Dispõe sobre Licenciamento Ambiental, Estudo de Impacto Ambiental e } \\
\text { Relatório de Impacto no Meio Ambiente de atividades e empreendimentos } \\
\text { com Organismos Geneticamente Modificados e seus derivados. }\end{array}$ \\
\hline$N^{\circ} 378 / 2006$ & $\begin{array}{l}\text { Alterada pela Resolução } n^{\circ} 428 / 2010 \text {. Define os empreendimentos } \\
\text { potencialmente causadores de impacto ambiental nacional ou regional para } \\
\text { fins do disposto no inciso III, } \$ 1^{\circ} \text {, art. } 19 \text { da Lei } n^{\circ} 4.771 / 1965 \text {, e dá outras } \\
\text { providências. }\end{array}$ \\
\hline$N^{\circ} 404 / 2008$ & $\begin{array}{l}\text { Estabelece critérios e diretrizes para o licenciamento ambiental de aterro } \\
\text { sanitário de pequeno porte de resíduos sólidos urbanos. }\end{array}$ \\
\hline$N^{\circ} 473 / 2015$ & 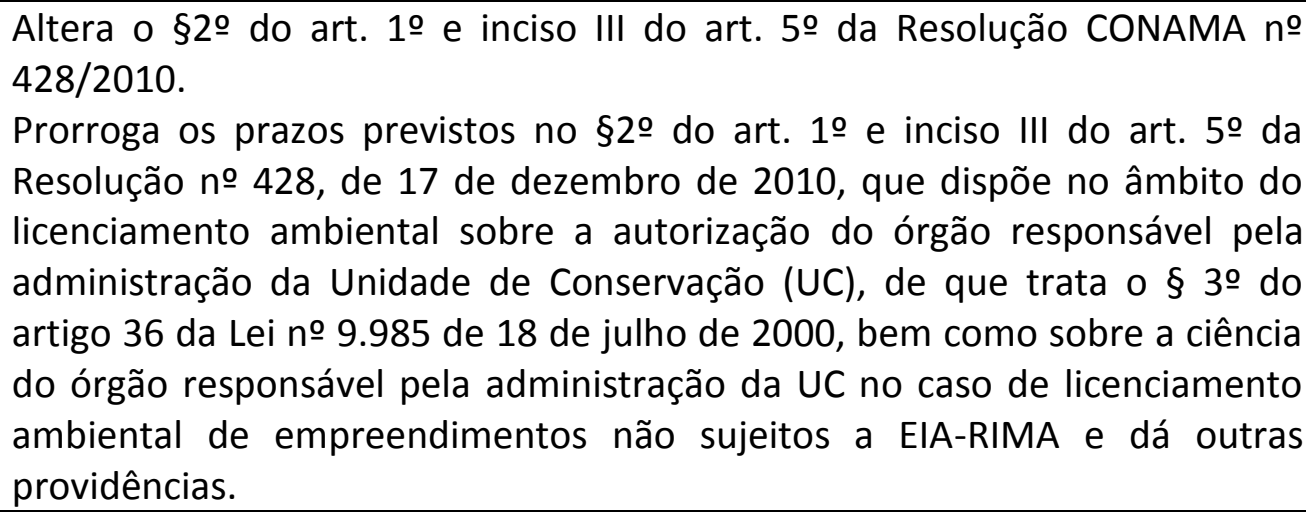 \\
\hline$N^{\circ} 466 / 2015$ & $\begin{array}{l}\text { Estabelece diretrizes e procedimentos para elaboração e autorização do } \\
\text { Plano de Manejo de Fauna em Aeródromos e dá outras providências. }\end{array}$ \\
\hline$N^{\circ} 4 / 1995$ & $\begin{array}{l}\text { Revogada pela Resolução 486/2018. Estabelece as Áreas de Segurança } \\
\text { Aeroportuária-ASAs. }\end{array}$ \\
\hline
\end{tabular}

Fonte: Elaborado pela autora (2018).

Tabela 3. Compilação das principais normas ABNT NBR relacionadas à implantação de aterro sanitário.

\begin{tabular}{c|l}
\hline $\begin{array}{c}\text { Normas da Associação Brasileira de } \\
\text { Normas Técnicas (ABNT) }\end{array}$ & \multicolumn{1}{c}{ Descrição } \\
\hline NBR n $8419 / 96$ & $\begin{array}{l}\text { Apresentação de projetos de aterros sanitários de } \\
\text { resíduos sólidos urbanos }\end{array}$ \\
\hline NBR n ${ }^{\circ} 13896 / 97$ & $\begin{array}{l}\text { Aterros de resíduos não perigosos - Critérios para } \\
\text { projeto, implantação e operação }\end{array}$ \\
\hline
\end{tabular}

Fonte: Elaborado pela autora (2018). 
Tabela 4. Portaria relacionada à implantação de aterro sanitário.

\begin{tabular}{c|l}
\hline \multicolumn{1}{c|}{ Portaria } & \multicolumn{1}{c}{ Descrição } \\
\hline Portaria COMAER n ${ }^{\circ} 741 / G C 3 / 2018$ & $\begin{array}{l}\text { Aprova a reedição do PCA 3-3, “Plano Básico de } \\
\text { Gerenciamento de Risco de Fauna nos aeródromos } \\
\text { brasileiros. }\end{array}$ \\
\hline
\end{tabular}

Fonte: Elaborado pela autora (2018).

Na Tabela 5, os dois primeiros critérios são referentes às faixas de distância de Áreas de Preservação Permanente (APP) e faixas de distância de cursos d'água, respectivamente. Esses dois critérios tratam de um assunto em comum, porém com definições e restrições diferentes. Desta forma, sugere-se usar a maior faixa de restrição como critério, a fim de obter maior proteção ambiental. Por exemplo, se o curso d'água tem largura de 10 a 50 metros, ao invés de se aplicar a faixa de distância da APP de 50 metros, determinada na Lei $n^{\circ} 12.651 / 2012$, sugere-se aplicar a faixa de distância proposta pela NBR $\mathrm{n}^{\circ} 13.896 / 87$ da $A B N T$, que é de 200 metros de qualquer coleção hídrica ou curso d'água. Além disso, para curso d'água com largura superior a 600 metros, sugere-se usar a faixa de distância de APP de 500 metros, assim, o empreendimento terá uma restrição maior quanto à proximidade de cursos d'água. Em relação ao critério "declividade" (Tabela 5), existem autores que sugerem outras variações de percentuais de declividade, como Moreira et al. (2008), porém deve-se analisar se a recomendação cabe à sua região de estudo.

No âmbito dos critérios socioeconômicos (Tabela 6), cabe ressaltar que a recente Resolução CONAMA ( $n^{\circ} 486 / 18$ ) revoga a questão de distância dos aeródromos, conforme consta na Resolução CONAMA $n^{\circ} 4 / 95$. Nesta resolução havia a restrição de um raio de $20 \mathrm{~km}$ para aeroportos que operam de acordo com as regras de voo por instrumento (IFR), e um raio de $13 \mathrm{~km}$ para os demais aeródromos. Desta forma, esse critério "distância dos aeródromos", que anteriormente era considerado restritivo, passa a ser considerado um critério ponderável. Ainda assim, exige-se a aprovação pela Portaria $n^{\circ} 741 / G C 3 / 18$ do Plano Básico de
Gerenciamento de Risco de Fauna nos aeródromos brasileiros. Esse Plano define que - Centro de Investigação e Prevenção de Acidentes Aeronáuticos - CENIPA é responsável pela emissão de parecer técnico sobre risco de fauna, e que este parecer técnico, é um instrumento de prevenção de acidentes aeronáuticos, relacionado a empreendimentos/atividades da ASA (Área de Segurança Aeroportuária) dos aeródromos brasileiros, aplicando-se à (ao):

“a) Autoridade municipal;

b) Autoridade ambiental municipal

c) Autoridade ambiental estadual;

d) Autoridade ambiental federal; e

e) interessado na operação de empreendimento ou atividade atrativa ou potencialmente atrativa de fauna no interior da ASA de aeródromo brasileiro."

Esse mesmo plano define, também, que ASA é:

"Área circular do território de um ou mais municípios, definida a partir do centro geométrico da maior pista do aeródromo ou do aeródromo militar, com $20 \mathrm{~km}$ (vinte quilômetros) de raio, cujos uso e ocupação estão sujeitos a restrições especiais, em função da natureza atrativa de fauna. O limite vertical da ASA é de 3.500 pés de altura (1.067 metros)."

Dentre os critérios de análise para emissão de parecer técnico pela CENIPA, observa-se que para Aterro Sanitário (recobrimento diário - material inerte), considera-se o potencial atrativo de aves como "muito alto" e parecer técnico "favorável" quando a distância do empreendimento for acima de $10 \mathrm{~km}$ até 20 $\mathrm{km}$. 
Salienta-se que, ainda assim, para definir possíveis áreas para implantação de aterro sanitário, é necessária a elaboração da licença ambiental, conforme definido por cada órgão ambiental e, consequentemente, elaborar o EIA/RIMA (Estudo de Impacto Ambiental e Relatório de Impacto Ambiental), conforme definido na Lei $n^{\circ}$ 6.938/1981. 
Tabela 5. Critérios ambientais restritivos e ponderáveis.

\begin{tabular}{|c|c|c|c|c|}
\hline \multicolumn{5}{|c|}{ CRITÉRIOS AMBIENTAIS } \\
\hline Critério & Restrição/Recomendação & $\begin{array}{l}\text { Tipo de } \\
\text { Critério }\end{array}$ & Fonte de informação & Fonte de dados \\
\hline APP & $\begin{array}{l}\text { Áreas de Preservação Permanente (APP) de: } \\
\text { a) } 30 \text { m para cursos d'água de menos de } 10 \\
\text { m; } \\
\text { b) } 50 \mathrm{~m} \text { para cursos d'água de } 10 \mathrm{~m} \text { a } 50 \mathrm{~m} \text {; } \\
\text { c) } 100 \mathrm{~m} \text { para cursos d'água de } 50 \mathrm{~m} \text { a } 200 \\
\text { m; } \\
\text { d) } 200 \mathrm{~m} \text { para cursos d'água de } 200 \mathrm{~m} \text { a } 600 \\
\text { m; } \\
\text { c) } 500 \mathrm{~m} \text { para cursos d'água superior a } 600 \\
\text { m; } \\
\text { Nascentes para raio mínimo de } 50 \mathrm{~m} \text {. }\end{array}$ & Restritivo & Lei № $12.651 / 2012$ & $\begin{array}{l}\text { Pode ser gerado em software de } \\
\text { SIG a partir dos dados de } \\
\text { hidrografia disponíveis no site do } \\
\text { IBGE na escala } 1: 250.000 \text {, ou no } \\
\text { site do DataGEO na escala } \\
\text { 1:50.000 (deve ser solicitado). }\end{array}$ \\
\hline $\begin{array}{l}\text { Proximidade } \\
\text { de cursos } \\
\text { d'água }\end{array}$ & $\begin{array}{l}\text { O aterro deve ser localizado a uma distância } \\
\text { mínima de } 200 \mathrm{~m} \text { de qualquer coleção } \\
\text { hídrica ou curso de água. }\end{array}$ & Restritivo & NBR $13.896 / 97$ & \\
\hline $\begin{array}{l}\text { Topografia } \\
\text { (Declividade) }\end{array}$ & $\begin{array}{l}\text { Recomendam-se locais com declividade } \\
\text { superior a } 1 \% \text { e inferior a } 30 \% \text {. }\end{array}$ & Ponderável & NBR 13.896/97 & $\begin{array}{l}\text { Pode ser gerado em software de } \\
\text { SIG a partir de dados de MDE } \\
\text { (Modelo Digital de Elevação) da } \\
\text { missão SRTM (Shuttle Radar } \\
\text { Topography Mission) de } 2000 \text { com } \\
\text { resolução espacial de } 30 \text { metros. }\end{array}$ \\
\hline
\end{tabular}




\begin{tabular}{|c|c|c|c|c|}
\hline $\begin{array}{l}\text { Geologia e } \\
\text { Pedologia }\end{array}$ & $\begin{array}{l}\text { Fator importante na determinação da } \\
\text { capacidade de depuração do solo e da } \\
\text { velocidade de infiltração. Considera-se } \\
\text { desejável a existência, no local, de um } \\
\text { depósito natural extenso e homogêneo de } \\
\text { materiais com coeficiente de } \\
\text { permeabilidade inferior a } 10-6 \mathrm{~cm} / \mathrm{s} \text { e uma } \\
\text { zona não saturada com espessura superior a } \\
3,0 \mathrm{~m} \text {. }\end{array}$ & Ponderável & NBR 13.896/97 & $\begin{array}{l}\text { Disponível no site do IBGE na } \\
\text { escala } 1: 250.000 \text {. }\end{array}$ \\
\hline Vegetação & $\begin{array}{l}\text { O estudo macroscópico da vegetação é } \\
\text { importante, uma vez que ela pode atuar } \\
\text { favoravelmente na escolha de uma área } \\
\text { quanto aos aspectos de redução do } \\
\text { fenômeno de erosão, da formação de poeira } \\
\text { e transporte de odores. }\end{array}$ & Ponderável & NBR 13.896/97 & \multirow[t]{2}{*}{$\begin{array}{l}\text { Disponível no site do IBGE na } \\
\text { escala 1:250.000. }\end{array}$} \\
\hline $\begin{array}{l}\text { Precipitação/ } \\
\text { Clima }\end{array}$ & $\begin{array}{l}\text { O aterro não deve ser executado em áreas } \\
\text { sujeitas a inundações, em períodos de } \\
\text { recorrência de } 100 \text { anos. }\end{array}$ & Restritivo & NBR 13.896/97 & \\
\hline Lençol Freático & $\begin{array}{l}\text { Entre a superfície inferior do aterro e o mais } \\
\text { alto nível do lençol freático deve haver uma } \\
\text { camada natural de espessura mínima de } \\
1,50 \mathrm{~m} \text { de solo insaturado. O nível do lençol } \\
\text { freático deve ser medido durante a época } \\
\text { de maior precipitação pluviométrica da } \\
\text { região. }\end{array}$ & Restritivo & NBR 13.896/97 & $\begin{array}{l}\text { Disponível no site do CPRM } \\
\text { (cadastro de poços com } \\
\text { informações de profundidade). }\end{array}$ \\
\hline $\begin{array}{l}\text { Unidade de } \\
\text { Conservação } \\
\text { (UC) }\end{array}$ & $\begin{array}{l}\text { As Unidades de Conservação são espaços } \\
\text { territoriais que possuem restrições quanto } \\
\text { ao uso. Com isso, essas áreas se tornam } \\
\text { inviáveis para a implantação de aterros } \\
\text { sanitários. }\end{array}$ & Restritivo & $\begin{array}{c}\text { Lei } \mathrm{n}^{\circ} 9.985 / 2000 \text { CONAMA } \\
428 / 2010\end{array}$ & $\begin{array}{l}\text { Disponível no site do IBGE na } \\
\text { escala 1:250.000. }\end{array}$ \\
\hline
\end{tabular}


Continuação da Tabela 5.

\begin{tabular}{|c|c|c|c|c|}
\hline Critério & Restrição/Recomendação & $\begin{array}{l}\text { Tipo de } \\
\text { Critério } \\
\end{array}$ & Fonte de informação & Fonte de dados \\
\hline Geomorfologia & $\begin{array}{l}\text { A análise geomorfológica consiste na } \\
\text { identificação e mapeamento das formas de } \\
\text { relevo, baseados no aspecto fisionômico das } \\
\text { formas de relevo, no seu significado } \\
\text { morfogenético e nas influências estruturais } \\
\text { e esculturais (ROSS, 1992). }\end{array}$ & Ponderável & 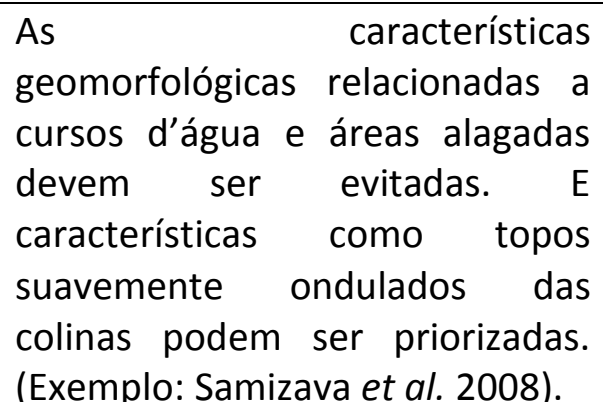 & \\
\hline
\end{tabular}

Fonte: Elaborada pela autora (2018).

Tabela 6. Critérios socioeconômicos restritivos e ponderáveis.

\begin{tabular}{|c|c|c|c|c|}
\hline \multicolumn{5}{|c|}{ CRITÉRIOS SOCIOECONÔMICOS } \\
\hline Critério & Restrição/Recomendação & $\begin{array}{l}\text { Tipo de } \\
\text { Critério }\end{array}$ & Fonte de informação & Fonte de dados \\
\hline $\begin{array}{l}\text { Distância } \\
\text { mínima dos } \\
\text { núcleos } \\
\text { populacionais }\end{array}$ & $\begin{array}{l}\text { Deve ser avaliada a distância do limite da } \\
\text { área útil do aterro a núcleos populacionais, } \\
\text { recomendando-se que esta distância seja } \\
\text { superior a } 500 \mathrm{~m} \text {. }\end{array}$ & Ponderável & NBR 13.896/97 & $\begin{array}{l}\text { Disponível no site do IBGE na escala } \\
1: 250.000\end{array}$ \\
\hline $\begin{array}{l}\text { Uso e } \\
\text { ocupação do } \\
\text { solo }\end{array}$ & $\begin{array}{l}\text { Pode ser restritivo (ex.: considerando } \\
\text { classes como: área urbana, vegetação e } \\
\text { cursos d'água como restritivo e o restante } \\
\text { das classes permissível) ou Ponderável (ex.: } \\
\text { As áreas têm que se localizar numa região } \\
\text { onde o uso do solo seja rural (agrícola) ou } \\
\text { industrial e fora de qualquer Unidade de } \\
\text { Conservação Ambiental. Dá-se a preferência } \\
\text { para áreas agrícolas e industriais, ou seja, } \\
\text { longe da população (Monteiro et al, 2001)). }\end{array}$ & $\begin{array}{l}\text { Restritivo/ } \\
\text { Ponderável }\end{array}$ & $\begin{array}{l}\text { Ex.: Motlagh et al. (2015), } \\
\text { Monteiro et al. (2001), } \\
\text { Nascimento \& Silva (2014). }\end{array}$ & $\begin{array}{l}\text { Pode ser gerado a partir da } \\
\text { classificação de imagens do satélite } \\
\text { Landsat } 8 \text {, sensor OLI, de } 30 \text { metros } \\
\text { de resolução espacial, corrigidas e } \\
\text { prontas para a classificação, na } \\
\text { página do Serviço Geológico dos } \\
\text { Estados Unidos - USGS } \\
\text { (https://www.usgs.gov/). }\end{array}$ \\
\hline
\end{tabular}


Continuação da Tabela 6.

\begin{tabular}{|c|c|c|c|c|}
\hline Critério & Restrição/Recomendação & $\begin{array}{l}\text { Tipo de } \\
\text { Critério }\end{array}$ & Fonte de informação & Fonte de dados \\
\hline $\begin{array}{l}\text { Direção e } \\
\text { Velocidade dos } \\
\text { Ventos }\end{array}$ & $\begin{array}{l}\text { Aconselha-se que o aterro sanitário não } \\
\text { esteja localizado em uma área cujos ventos } \\
\text { predominantes soprem na direção da área } \\
\text { urbana, visto que, mesmo que o aterro seja } \\
\text { bem operado, os odores provenientes da } \\
\text { decomposição dos resíduos podem causar } \\
\text { desconforto para a população. A lógica do } \\
\text { processo é fazer com que o aterro fique } \\
\text { localizado numa área onde os ventos } \\
\text { passem primeiro pela área urbanizada e } \\
\text { depois pelo aterro. O contrário constitui um } \\
\text { cenário inapropriado. }\end{array}$ & Ponderável & Ex.: Nascimento \& Silva (2014) & $\begin{array}{l}\text { Verificar estudos disponíveis sobre a } \\
\text { área de interesse. }\end{array}$ \\
\hline $\begin{array}{l}\text { Densidade } \\
\text { Demográfica }\end{array}$ & $\begin{array}{l}\text { Densidade cima de } 1000 \text { habitantes por } \mathrm{km}^{2} \\
\text { foram considerados como restritos dentro } \\
\text { dos fatores dos critérios restritivos sociais. }\end{array}$ & Ponderável & Ex.: Nascimento (2012) & $\begin{array}{l}\text { Pode ser gerado em software de SIG } \\
\text { a partir dos dados de densidade } \\
\text { demográfica disponíveis pelo IBGE }\end{array}$ \\
\hline $\begin{array}{l}\text { Acessos/ } \\
\text { Distância de } \\
\text { Estradas }\end{array}$ & $\begin{array}{l}\text { Fator de evidente importância em um } \\
\text { projeto de aterro, uma vez que são } \\
\text { utilizados durante toda a sua operação (NBR } \\
\text { 13.896/97). }\end{array}$ & Ponderável & $\begin{array}{l}\text { NBR 13.896/97 } \\
\text { Ex.: Samizava et al. (2008) } \\
\text { consideraram "Distâncias de } 0 \text { a } \\
200 \text { metros, de } 200 \text { a } 500 \text { metros } \\
\text { (mais favorável), maior que } 1000 \\
\text { metros (menos favorável) das } \\
\text { principais vias de acesso". }\end{array}$ & $\begin{array}{l}\text { Disponível no site do IBGE na escala } \\
1: 250.000\end{array}$ \\
\hline Custo & $\begin{array}{l}\text { Os custos de um aterro têm grande } \\
\text { variabilidade conforme o seu tamanho e o } \\
\text { seu método construtivo. A elaboração de } \\
\text { um cronograma físico-financeiro é } \\
\text { necessária para permitir a análise de } \\
\text { viabilidade econômica do empreendimento. }\end{array}$ & Ponderável & NBR 13.896/97 & $\begin{array}{l}\text { Verificar estudos disponíveis sobre a } \\
\text { área de interesse. }\end{array}$ \\
\hline
\end{tabular}


Continuação da Tabela 6.

\begin{tabular}{|c|c|c|c|c|}
\hline Critério & Restrição/Recomendação & $\begin{array}{l}\text { Tipo de } \\
\text { Critério }\end{array}$ & Fonte de informação & Fonte de dados \\
\hline $\begin{array}{l}\text { Distância de } \\
\text { Aeroportos }\end{array}$ & $\begin{array}{l}\text { - Raio de } 20 \mathrm{~km} \text { para aeroportos que } \\
\text { operam de acordo com as regras de voo por } \\
\text { instrumento (IFR); e Raio de } 13 \mathrm{~km} \text { para os } \\
\text { demais aeródromos (Resolução CONAMA } \\
\text { 04/95 Revogada pela Resolução CONAMA } \\
\text { 486/18). } \\
\text { - Empreendimento a ser implantado com } \\
\text { distância acima de } 10 \mathrm{~km} \text { até } 20 \mathrm{~km}= \\
\text { parecer favorável do CENIPA (Centro de } \\
\text { Investigação e Prevenção de Acidentes } \\
\text { Aeronáuticos), conforme Plano Básico de } \\
\text { Gerenciamento de Risco de Fauna dos } \\
\text { aeródromos brasileiros (2018). }\end{array}$ & Ponderável & $\begin{array}{l}\text { - Resolução CONAMA 004/95 } \\
\text { Revogada pela Resolução } \\
\text { CONAMA n086/18. } \\
\text { - Plano Básico de Gerenciamento } \\
\text { de Risco de Fauna nos } \\
\text { aeródromos brasileiros (2018). }\end{array}$ & $\begin{array}{l}\text { Dados da localização de aeródromos } \\
\text { disponíveis no site da ANAC. Pode- } \\
\text { se gerar faixas de distância em } \\
\text { software de SIG. }\end{array}$ \\
\hline
\end{tabular}




\section{CONSIDERAÇÕES FINAIS}

A elaboração de estudos para definição de áreas apropriadas para a implantação de aterro sanitário é uma tarefa complexa e exige o conhecimento prévio de leis, resoluções, normas e portarias vigentes. Com este trabalho, que apresenta de forma compilada as principais leis, resoluções, normas e portaria em nível federal, bem como, os principais critérios restritivos e ponderáveis nas esferas ambiental e socioeconômica, é possível observar de forma organizada e simples quais critérios e quais questões necessárias para implantação de um aterro sanitário.

Nota-se que existem diversos critérios ponderáveis, porém, devido à dificuldade de encontrar alguns dados e a generalidade de algumas informações, pode-se optar por considerar apenas alguns destes critérios ponderáveis, que sejam pertinentes à área de estudo. Caso contrário, a identificação da área para aterro sanitário pode tornar-se inviável ou limitada.

Concluímos que este trabalho contribui para a facilitar o entendimento e o acesso às leis, resoluções, normas e portarias vigentes, relacionadas a implantação de aterro sanitário. Porém, ressaltamos que o conhecimento dessas diretrizes não é o bastante e que, há a necessidade ainda de elaboração de licenças ambientais, nos quais exigem estudos mais detalhados e análises específicas para, assim, definir a área para implantação de aterro sanitário.

\section{AGRADECIMENTOS}

Agradecimento ao Núcleo de Estudos Ambientais e Geoprocessamento - NEAGEO da Universidade do Oeste Paulista - UNOESTE e a Coordenação de Aperfeiçoamento de Pessoal de Nível Superior (CAPES).

\section{REFERÊNCIAS}

ASSOCIAÇÃO BRASILEIRA DE NORMAS TÉCNICAS (ABNT). Apresentação de projetos de aterros sanitários de resíduos sólidos urbanos. NBR 8.419: .1996. Disponível em: https://www.observatorioderesiduos.unb.br/ painel/assets/uploads/files/996de-nbr-8.419nb-843-apresentacao-de-projetos-de-aterrossanitarios-rsu.pdf. Acesso em: 20 jul. 2018.

ASSOCIAÇÃO BRASILEIRA DE NORMAS TÉCNICAS (ABNT). Aterros de resíduos não perigosos - Critérios para projeto, implantação e operação. NBR 13896: 1997. Disponível

em: http://www2.fct.unesp.br/docentes/plan/cris rizk/Gerenciamento\%20de\%20Residuos\%20S olidos/NBR_13896\%20-

\%20aterro\%20de\%20res\%EDudos\%20nao\%20 perigosos.pdf. Acesso em: 20 jul. 2018.

ABRELPE - ASSOCIAÇÃO BRASILEIRA DAS EMPRESAS DE LIMPEZA PÚBLICA E RESÍDUOS ESPECIAIS. Panorama dos Resíduos Sólidos no Brasil, [S.I.: s. n.], 2016. Disponível em: http://www.abrelpe.org.br/Panorama/panora ma2016.pdf. Acesso em: 17 jun. 2018.

BRASIL. Congresso Nacional. Lei $n^{\circ} 5.197$ de 3 de janeiro de 1967. Dispõe sobre a proteção à fauna e dá outras providências. Diário Oficial da União, Brasília, DF, 05 jan. 1967. Disponível em: http://www.planalto.gov.br/ccivil_03/leis/L51 97compilado.htm. Acesso em: 18 jul. 2018.

BRASIL. Congresso Nacional. Lei $n^{\circ} 6.938$ de 31 de agosto de 1981. Dispõe sobre a Política Nacional do Meio Ambiente, seus fins e mecanismos de formulação e aplicação, e dá outras providências. Diário Oficial da União, Brasília, DF, 02 set. 1981. Disponível em: http://www.planalto.gov.br/ccivil_03/LEIS/L6 938.htm. Acesso em: 18 jul. 2018.

BRASIL. Congresso Nacional. Lei $n^{\circ} 7.653$ de 2 de fevereiro de 1988. Altera a redação dos arts. 18, 27, 33 e 34 da Lei no 5.197, de 3 de janeiro de 1967, que dispõe sobre a proteção à fauna, e dá outras providências. Diário Oficial da União, Brasília, DF, 17 fev. 1988. Disponível em: < http://www.planalto.gov.br/ccivil_03/leis/L76 53.htm>. Acesso em: 18 jul. 2018. 
BRASIL. Congresso Nacional. Lei $\mathrm{n}^{\circ} 9.605$ de 12 de fevereiro de 1998. Dispõe sobre as sanções penais e administrativas derivadas de condutas e atividades lesivas ao meio ambiente, e dá outras providências. Diário Oficial da União, Brasília, DF, 13 fev. 1998. Disponível em: http://www.planalto.gov.br/ccivil_03/LEIS/L9 605.htm. Acesso em: 18 jul. 2018.

BRASIL. Congresso Nacional. Lei $n^{\circ} 9.985$ de 18 de julho de 2000. Regulamenta o art. 225, $\S 10$, incisos I, II, III e VII da Constituição Federal, institui o Sistema Nacional de Unidades de Conservação da Natureza e dá outras providências. Diário Oficial da União, Brasília, DF, 19 jul. 2000. Disponível em: http://www.planalto.gov.br/ccivil_03/LEIS/L9 985.htm. Acesso em: 18 jul. 2018.

BRASIL. Congresso Nacional. Lei $n^{\circ} 11.284$ de 2 de março de 2006. Dispõe sobre a gestão de florestas públicas para a produção sustentável; institui, na estrutura do Ministério do Meio Ambiente, o Serviço Florestal Brasileiro - SFB; cria o Fundo Nacional de Desenvolvimento Florestal FNDF; altera as Leis nos 10.683, de 28 de maio de 2003, 5.868, de 12 de dezembro de 1972, 9.605, de 12 de fevereiro de 1998, 4.771, de 15 de setembro de 1965, 6.938, de 31 de agosto de 1981, e 6.015, de 31 de dezembro de 1973; e dá outras providências. Diário Oficial da União, Brasília, DF, 03 mar. 2006. Disponível em: http://www.planalto.gov.br/ccivil_03/_ato20 04-2006/2006/lei/l11284.htm. Acesso em: 20 jul. 2018.

BRASIL. Congresso Nacional. Política Nacional de Resíduos Sólidos. Lei $\mathrm{n}^{\circ} 12.305$ de 2 de agosto de 2010. Institui a Política Nacional de Resíduos Sólidos; altera a Lei no 9.605, de 12 de fevereiro de 1998; e dá outras providências. Diário Oficial da União, Brasília, DF, 03 ago. 2010, p.2. Disponível em: http://www.planalto.gov.br/ccivil_03/_ato20 07-2010/2010/lei/l12305.htm. Acesso em: 20 jul. 2018.
BRASIL. Congresso Nacional. Lei $n^{\circ} 12.651$ de 25 de maio de 2012. Dispõe sobre a proteção da vegetação nativa; altera as Leis nos 6.938, de 31 de agosto de 1981, 9.393, de 19 de dezembro de 1996, e 11.428, de 22 de dezembro de 2006; revoga as Leis nos 4.771, de 15 de setembro de 1965, e 7.754, de 14 de abril de 1989, e a Medida Provisória no 2.16667, de 24 de agosto de 2001; e dá outras providências. Diário Oficial da União, Brasília, DF, 28 mai. 2012. Disponível em: < http://www.planalto.gov.br/cciviL_03/_Ato20 11-2014/2012/Lei/L12651.htm>. Acesso em: 20 jul. 2018.

BRASIL. Congresso Nacional. Portaria $n^{\circ} 741 /$ GC3 de 23 de maio de 2018. Aprova a reedição do PCA 3-3, "Plano Básico de Gerenciamento de Risco de Fauna nos aeródromos brasileiros". Diário Oficial da União, Brasília, DF, 24 mai. 2018. Seção 1. P. 17. Disponível em: < http://www2.fab.mil.br/cenipa/index.php/leg islacao/pca-plano-do-comando-da-

aeronautica?download=130:pca-3-3>. Acesso em: 24 jul. 2018.

CONAMA, Resolução. $N^{\circ} 04$, de 09 de outubro de 1995. Revogada pela Resolução no 486/2018 Estabelece as Áreas de Segurança Aeroportuária - ASAs. Conselho Nacional do Meio Ambiente-CONAMA. Diário Oficial da União, Brasília, DF, 11 dez. 1995, Seção 1, p. 20388. Disponível em: http://www.mma.gov.br/port/conama/legiab re.cfm?codlegi=182. Acesso em 23 jul. 2018.

CARRILHO, A. N.; CANDIDO, H. G.; SOUZA, A. D. Geoprocessamento aplicado na seleção de áreas para a implantação de aterro sanitário no município de Conceição das Alagoas (MG). Eng. Sanit. Ambient. Rio de Janeiro, v. 23, n. 1, p. 201-206, Feb. 2018. Disponível em: https://www.sciencedirect.com/science/articl e/pii/S0956053X18302599?via\%3Dihub.

Acesso em: 26 jul. 2018.

COLVERO, D. A.; GOMES, A. P. D.; DA CRUZ TARELHO, L. A.; DE MATOS, M. A. A.; SANTOS, 
K. A. Use of a geographic information system to find areas for locating of municipal solid waste management facilities. Waste Management. 2018. Disponível em: https://www.sciencedirect.com/science/articl e/pii/S0956053X18302599?via\%3Dihub.

Acesso em: 26 jul. 2018.

DE FEO, G.; DE GISI, S. Using MCDA and GIS for hazardous waste landfill siting considering land scarcity for waste disposal. Waste management, v. 34, n. 11 , p. 2225-2238, $2014 . \quad$ Disponível em: https://www.sciencedirect.com/science/articl e/pii/S0956053X14002591. Acesso em: 25 jul. 2018.

DEMESOUKA, O. E.; VAVATSIKOS, A. P.; ANAGNOSTOPOULOS, K. P. GIS-based multicriteria municipal solid waste landfill suitability analysis: A review of the methodologies performed and criteria implemented. Waste Management \& Research, v. 32, n. 4, p. 270-296, 2014. Disponível em: http://journals.sagepub.com/doi/abs/10.1177 /0734242X14526632. Acesso em: 27 jul. 2018.

Motlagh, Z. K.; SAYADI, M. H. Siting MSW landfills using MCE methodology in GIS environment (Case study: Birjand plain, Iran). Waste management, v. 46, p. 322-337, 2015. Disponível em: https://www.sciencedirect.com/science/articl e/pii/S0956053X15300817. Acesso em: 27 jul. 2018.

NASCIMENTO, V. F.; DA SILVA, A. M. Identifying problems for choosing suitable areas for installation of a new landfill through GIS technology: A case study. Journal of the Air \& Waste Management Association, 64(1), 80-88. 2014. Disponível em:< https://www.tandfonline.com/doi/full/10.108 0/10962247.2013.833558>. Acesso em: 27 jul. 2018.

NASCIMENTO, V. F. Proposta para indicação de áreas para a implantação de aterro sanitário no município de Bauru - SP, utilizando análise multi critério de decisão e técnicas de geoprocessamento. 2012. Dissertação (Mestrado) - Universidade Estadual Paulista, Faculdade de Engenharia, 2012. Disponível em: http://hdl.handle.net/11449/92957. Acesso em: 24 jul. 2018.

RAHMAT, Z. G. et al. Landfill site selection using GIS and AHP: a case study: Behbahan, Iran. KSCE Journal of Civil Engineering, v. 21, n. 1, p. 111-118, 2017. Disponível em: https://link.springer.com/article/10.1007/s12 205-016-0296-9. Acesso em: 26 jul. 2018.

SPIGOLON, L. M.; GIANNOTTI, M.; LAROCCA, A. P.; RUSSO, M. A.; SOUZA, N. D. C. Landfill siting based on optimisation, multiple decision analysis, and geographic information system analyses. Waste Management \& Research, $0734242 \times 18773538.2018$. Disponível em: http://journals.sagepub.com/doi/10.1177/07 34242X18773538. Acesso em: 27 jul. 2018.

TORABI-KAVEH, M.; BABAZADEH, R.; MOHAMMADI, S. D.; ZARESEFAT, M. Landfill site selection using combination of GIS and fuzzy AHP, a case study: Iranshahr, Iran. Waste Management \& Research, v. 34, n. 5, p. 438-448. 2016. Disponível em: http://journals.sagepub.com/doi/10.1177/07 34242X16633777. Acesso em: 27 jul. 2018. 